\title{
Evaluation of Cognition and Cortical Excitability in Huntington's Disease
}

\author{
Nitish Kamble, M. Netravathi, B.C. Nagaraju, Abhishek Lenka, Keshav Kumar, \\ V. Sowmya, Sanjeev Jain, Pramod Kumar Pal
}

\begin{abstract}
Background: Recent advances in neurophysiological techniques have contributed to our understanding of the pathophysiology of Huntington's disease (HD). Studies of the motor cortical excitability and central motor pathways have shown variable results. Objectives: Our aims were to evaluate the cortical excitability changes in HD using transcranial magnetic stimulation (TMS) and correlate the changes with cognitive impairment. Methods: The study included 32 HD patients and 30 age- and gender-matched controls. The demographic and clinical profiles of the patients were recorded. All subjects were evaluated by TMS and resting motor threshold (RMT), central motor conduction time (CMCT), silent period (SP), short-interval intracortical inhibition (SICI), and intracortical facilitation were determined. A battery of neuropsychological tests was administered to all subjects. Results: The mean age of the patients was $42.1 \pm 14.1$ years, and that of controls $39.4 \pm 12.4$ years $(p=0.61)$. There was no significant difference in RMT and CMCT between the two groups. There was a mild prolongation of the contralateral SP in HD, but it was not significant. SICI was significantly reduced in $\mathrm{HD}(p<0.0001)$. A significant impairment in attention, verbal fluency, executive function, visuospatial function, learning, and memory was observed in HD patients. However, there was no correlation between cortical excitability changes and cognitive impairment. Conclusions: TMS is a valuable method of evaluating cortical excitability changes in HD. These patients have reduced SICI and significant impairment of cognition in multiple domains.
\end{abstract}

RÉSUMÉ: Évaluation des fonctions cognitives et de l'excitabilité des zones corticales chez des patients atteints de la maladie de Huntington. Contexte: Des progrès récents dans les techniques neurophysiologiques nous ont permis de mieux comprendre la physiopathologie de la maladie de Huntington (MH). Des études portant sur l'excitabilité des zones corticales motrices et sur les voies centrales motrices ont toutefois débouché sur des résultats variables. Objectifs: C'est au moyen de la stimulation magnétique transcrânienne (SMT) que nous avons cherché, en ce qui regarde la MH, à évaluer les variations de l'excitabilité des zones corticales. Nous avons aussi cherché à établir une corrélation entre ces variations et une dégradation des facultés cognitives. Méthodes: Notre étude a inclus 32 patients atteints de la MH et 30 témoins appariés selon l'âge et le sexe. Les profils démographiques et cliniques des patients ont été ensuite consignés. Tous les sujets de l'étude ont été évalués au moyen de la SMT ; ont été déterminés les seuils moteur au repos (SMR), les temps de conduction centrale (TCC), les intervalle de silence électro-cérébral, les processus d'inhibition intra-corticale à court intervalle ainsi que les processus de facilitation intra-corticale. Une série de tests neuropsychologiques ont également été administrés à tous les sujets de l'étude. Résultats: L'âge moyen des patients était de $42,1 \pm 14,1$ ans ; celui des témoins, $39,4 \pm 12,4$ ans $(p=0,61)$. Aucune différence notable n'a été observée entre ces deux groupes quant aux SMR et aux TCC. Un allongement modéré de l'intervalle controlatéral de silence électro-cérébral a aussi été noté dans le cas de la MH mais il ne s'est pas avéré significatif. Les résultats en matière de processus d'inhibition intra-corticale à court intervalle ont été réduits de façon importante dans le cas de la MH $(p<0,0001)$. Ajoutons qu'une dégradation cognitive importante a été rapportée chez les patients atteints de la MH, et ce, pour plusieurs fonctions : l'attention, la fluidité verbale, l'exécution de tâches, l'exploration visuo-spatiale, l'apprentissage et la mémoire. Cela dit, aucune corrélation n'a pu être établie entre des variations de l'excitabilité des zones corticales et une dégradation des facultés cognitives. Conclusions: La SMT constitue une méthode utile pour évaluer les variations de l'excitabilité des zones corticales dans le cas de patients atteints de la MH. Ces derniers ont donné à voir des processus d'inhibition intra-corticale à court intervalle réduits ainsi qu'une dégradation importante de nombreuses fonctions cognitives.

Keywords: Huntington's disease, Transcranial magnetic stimulation, Neuropsychology, Motor threshold, Silent period, Paired stimulation doi: $10.1017 / \operatorname{cjn} .2017 .277$

Can J Neurol Sci. 2018; 45: 176-181

\section{INTRODUCTION}

Huntington's disease (HD) is an autosomal dominant chronic progressive neurodegenerative disorder due to abnormal expansion of CAG (cytosine-adenine-guanine) trinucleotide repeats in the Huntingtin gene (HTT) located on chromosome $4 p$ that codes for the protein huntingtin. ${ }^{1}$ Although the exact biological functions of huntingtin is not fully understood, intracellular aggregates of this protein leads to mitochondrial dysfunction, with generation of reactive oxygen species, ATP depletion, and oxidative damage resulting in cell death. ${ }^{2}$ In addition to involuntary movements in the form of chorea, patients with HD may also present with several behavioral symptoms, including depression, mood disorders, psychosis, and cognitive impairment. ${ }^{3,4}$ The pathologic process

From the Departments of Neurology (NK, MN, BCN, AL, PKP); Clinical Neurosciences (AL); Clinical Psychology (KK), and Psychiatry (VS, SJ), of the National Institute of Mental Health and Neurosciences, Karnataka, India.

Received May 13, 2017. Final Revisions Submitted August 26, 2017. Date of ACCePtance SePtember 11, 2017.

Correspondence to: Pramod Kumar Pal, Department of Neurology, National Institute of Mental Health and Neurosciences, Bangalore 560029, India. Email: palpramod@ hotmail.com 
involves selective loss of GABAergic neurons of the striatum with initial involvement of caudate and later putamen ${ }^{5}$ that results in reduced inhibition of the thalamus and overstimulation of the cerebral cortex through the excitatory glutaminergic projections.

Previous studies have shown cognitive decline in various stages of the disease as well as in the prodrome, years before the onset of motor symptoms. ${ }^{6}$ The impairment is seen on tests of attention, verbal fluency, psychomotor speed, executive functioning, learning and memory, emotional processing, and visuospatial functioning. ${ }^{7,8}$ Long-term memory is spared until late in the illness. ${ }^{9}$

There is a growing interest in understanding the behavioral and cognitive changes in HD patients for several reasons. These behavioral and cognitive abnormalities impose a great burden on caregivers and families, and demonstrate disease-specific volume loss on MRI. ${ }^{10-12}$ As a result, studies of cognition in HD are emerging exponentially in order to develop valid and reliable measures of cognition in the prodromal as well as later stages.

Transcranial magnetic stimulation (TMS) is a noninvasive tool to evaluate the integrity of neural circuitry, and any abnormality may suggest neurotransmitter abnormalities in HD, which in turn may reflect the basis for motor and cognitive impairment in specific domains. TMS-based studies in patients with HD have yielded conflicting results, and hence the alterations in the neural circuitry in these patients has not been fully understood.

We therefore undertook this study to evaluate the cortical excitability changes using TMS and to understand the pathophysiological mechanisms underlying the disease. The other objective was to correlate the cortical excitability changes with cognitive dysfunction.

\section{Methods}

\section{Subjects}

The prospective study was conducted in the Department of Neurology at the National Institute of Mental Health and Neurosciences in Bangalore, India, and it was approved by its ethics committee. Thirty-two consecutive HD patients aged more than 18 and 30 age- and gender-matched healthy volunteers who gave written informed consent after having the nature and design of the study explained to them were included in the study. Subjects with a history of seizure, metallic implants in their body, cardiac pacemakers, and cochlear implants were excluded. All patients were clinically examined by a senior movement disorder specialist (PKP) and severity of the motor symptoms was scored using the motor part of the Unified Huntington Disease Rating Scale (UHDRS). ${ }^{13}$

Genetic testing was performed in all patients in order to confirm the diagnosis of HD. CAG repeat length (from region 5' of the HTT gene) was determined after polymerase chain reaction amplification of genomic DNA obtained from the peripheral blood of HD patients.

Both patients and controls underwent TMS and neuropsychological tests. Medications that can affect cortical excitability changes (e.g., benzodiazepines, carbamazepine, tetrabenazine) were stopped a week prior to these tests.

\section{TMS Methodology}

TMS was administered using two Magstim-200 stimulators connected through a bistim module. Subjects were allowed to sit comfortably on a chair, and magnetic stimuli were given using a handheld figure-of-eight coil with an inner diameter of $70 \mathrm{~mm}$ over the left primary motor cortex, and responses were recorded from the right first dorsal interosseus (FDI) muscle using $\mathrm{Ag}-\mathrm{AgCl}$ surface electrodes arranged in a belly-tendon montage. The stimulus intensity was increased in a stepwise manner until a satisfactory motor-evoked potential (MEP) was obtained. The area of optimal MEP (hotspot) was marked over the scalp, and subsequently the coil was positioned on the same area at an angle of $45^{\circ}$ pointing backward, and was evaluated for resting motor threshold (RMT), central motor conduction time (CMCT), silent period (SP), short-interval intracortical inhibition (SICI), and intracortical facilitation (ICF).

RMT was defined as the minimum stimulus intensity required to evoke peak-to-peak MEPs from a relaxed FDI to a minimum $50 \mu \mathrm{V}$ peak-to-peak in at least 5 out of 10 trials. Stimulus was given only after ensuring complete relaxation of the muscle under audiovisual guidance. In order to determine the CMCT, MEPs were recorded using $120 \%$ of the RMT. The CMCT was then calculated using the F-wave method. F-waves were recorded from the FDI after electrically stimulating the right ulnar nerve at the wrist with a supramaximal stimulus. A total of 20 recordings were taken. and the F-wave latency was measured. The CMCT was calculated using the formula

$$
\mathrm{CMCT}=\mathrm{MEP}-(\mathrm{F}+\mathrm{M}-1) / 2,
$$

where MEP is the MEP latency, $\mathrm{F}$ is the F-wave latency, and $\mathrm{M}$ is the M-wave latency. ${ }^{14}$ The contralateral SP (cSP) was recorded from the partially contracted right FDI muscle (30\% of maximal contraction) with a stimulus intensity of $120 \%$ of the RMT under audiovisual feedback to ensure the same amount of muscle contraction during each stimulus.

In a paired stimulation study, an initial conditioning stimulus (CS) that is subthreshold ( $80 \%$ of the RMT) was given followed by a second test stimulus (TS) at a suprathreshold level (120\% of the RMT). The interval between the TS and CS, known as the interstimulus interval (ISI), was fixed at 3 and $10 \mathrm{~ms}$. The recording included three conditions: a single-pulse TMS at $120 \%$ of the RMT, a paired pulse with a 3-ms ISI, and a paired pulse with a 10-ms ISI. Ten responses were obtained for each of the conditions. The mean amplitude of the MEP obtained after paired stimulation at each ISI was expressed as the ratio of the mean amplitude obtained by paired stimulus (CS + TS) to unconditioned TS (single-pulse TMS). The response obtained at an ISI of $3 \mathrm{~ms}$ was documented as SICI, and that obtained at $10 \mathrm{~ms}$ was documented as ICF. ${ }^{15}$

\section{Neuropsychological Battery}

Cognitive assessment was done in both patients and controls using a battery of selected neuropsychological tests that included the Mini-Mental Status Examination (MMSE), a frontal assessment battery (FAB) ${ }^{16}$ the Montreal Cognitive Assessment (MoCA, v. 7.1; www.mocatest.org), digit span forward and backward, a verbal fluency test (controlled word-association test and animal-naming test), the Corsi block-tapping test, ${ }^{17}$ response inhibition (the Stroop test), ${ }^{7,18}$ Rey's auditory verbal and learning test (AVLT), and a validated story recall test. These tests were done prior to administration of TMS.

\section{Statistical Analysis}

Statistical analysis was carried out using R software. Data were expressed using descriptive statistics (e.g., for continuous 
variables, means and standard deviations; and for categorical variables, frequency and percentage). Comparison between continuous variables was done using an independent Student's $t$ test and a chi-square test for categorical variables. Correlation between continuous variables was done using Pearson's correlation coefficient. A value of $p<0.05$ was considered statistically significant.

\section{Results}

\section{Demography and Clinical Characteristics (see Table 1)}

Some 32 HD patients( 12 women and 20 men) and 30 controls (13 women and 17 men) were included in our study. The mean age of patients was $42.1 \pm 14.1$ and that of controls $39.4 \pm 12.4$ years $(p=0.61)$. The mean age at onset of symptoms was $38.5 \pm 10.9$ years, with a range of 20-58 years (men $39.8 \pm 11.0$ years, range $=25-58$ years; women $36.6 \pm 10.9$ years, range $=20-54$ years). The mean UHDRS score was $36.4 \pm 13.3$, with a range between 15 and 78. The mean CAG repeat length was $45.2 \pm 6.1$ (range $=40-73)$.

\section{TMS parameters (see Table 2)}

\section{Single-Pulse Stimulation}

The RMT in patients was $36.6 \pm 12.3 \%$ and that in controls $33.2 \pm 5.7 \%(p=0.17)$. The CMCT in patients was $7.8 \pm 2.2 \mathrm{~ms}$ and in controls $7.3 \pm 2.0 \mathrm{~ms}(p=0.38)$. Prolongation of the cSP was observed in HD patients at $97.9 \pm 51.0 \mathrm{~ms}$ in comparison to controls $(80.1 \pm 23.3 \mathrm{~ms})$, but the difference was not significant $(p=0.09)$.

\section{Paired Stimulation}

SICI and ICF were measured as a ratio of the MEP amplitude obtained after combined CS and TS to TS alone (CS + TS/TS). A ratio of more than 1 suggests enhancement of MEP (ICF) and less than 1 suppression of MEP (SICI). At an ISI of $3 \mathrm{~ms}$, the change in MEP amplitude in patients was $1.64 \pm 1.3$ compared to $0.56 \pm 0.28$ in controls, suggesting a reduction in SICI that was significant $(p<0.001)$. ICF was observed in both groups, but it was not statistically significant $(p=0.38)$.

\section{Correlation of TMS Parameters with UHDRS Score, CAG Repeat Length, and Disease Duration}

Correlation analysis was carried out between TMS parameters and such disease parameters as CAG repeat length and UHDRS motor scores. None of them showed any significant correlation

Table 1: Patient characteristics

\begin{tabular}{l|l}
\hline Total patients & 32 \\
\hline Gender (women/men) & $12 / 20$ \\
\hline Age (mean $\pm S D)$ & $42.1 \pm 14.1$ years \\
\hline Age at onset $($ mean $\pm S D)$ & $38.5 \pm 10.9$ years \\
\hline Duration of illness $($ mean $\pm S D)$ & $48.4 \pm 24.6$ months \\
\hline CAG repeat length $($ mean $\pm S D)$ & $45.2 \pm 6.1$ \\
\hline UHDRS score (mean $\pm S D)$ & $36.4 \pm 13.3$ \\
\hline
\end{tabular}

UHDRS $=$ Unified Huntington Disease Rating Scale.
Table 2: Comparison of TMS parameters between cases and controls

\begin{tabular}{l|c|c|c}
\hline TMS Parameters & Patients (32) & Controls (30) & Value of $\boldsymbol{P}$ \\
\hline $\mathrm{RMT}(\%)$ & $36.6 \pm 12.3$ & $33.2 \pm 5.7$ & 0.17 \\
\hline $\mathrm{CMCT}(\mathrm{ms})$ & $7.8 \pm 2.2$ & $7.3 \pm 2.0$ & 0.38 \\
\hline Contralateral SP (ms) & $97.9 \pm 51.0$ & $80.1 \pm 23.3$ & 0.09 \\
\hline $\mathrm{SICl}_{3 \mathrm{~ms}}(\mathrm{CS}-\mathrm{TS} / \mathrm{TS})$ & $1.64 \pm 1.3$ & $0.56 \pm 0.28$ & $<0.001$ \\
\hline $\mathrm{ICF}_{10 \mathrm{~ms}}(\mathrm{CS}-\mathrm{TS} / \mathrm{TS})$ & $2.16 \pm 1.61$ & $2.7 \pm 1.16$ & 0.15 \\
\hline
\end{tabular}

$\mathrm{CMCT}=$ central motor conduction time; $\mathrm{CS}=$ conditioning stimulus; $\mathrm{ICF}=$ intracortical facilitation; RMT $=$ resting motor threshold; SICI $=$ shortinterval intracortical inhibition; $\mathrm{SP}=$ silent period; $\mathrm{TS}=$ test stimulus.

with the TMS parameters. There was also no correlation between SICI and disease duration $(p=0.76)$.

\section{Neuropsychological Assessment (see Table 3 and Figure 1)}

A statistically significant difference was observed between HD patients and controls for all the neuropsychological tests $(p<0.001)$, suggesting impairment of memory, learning, and visuospatial and executive functions in HD. In Rey's AVLT, HD patients seem to have some preservation of learning, as shown in Figure 1.

Table 3: Neuropsychological assessment of subjects

\begin{tabular}{l|c|c|c}
\hline Neuropsychological test & Patients $(\boldsymbol{n}=\mathbf{3 2})$ & Controls $(\boldsymbol{n}=\mathbf{3 0})$ & Value of $\boldsymbol{p}$ \\
\hline MMSE & $24.9 \pm 4.3$ & $29.6 \pm 0.6$ & $<0.001$ \\
\hline MoCA & $22.9 \pm 4.6$ & $29.4 \pm 0.73$ & $<0.001$ \\
\hline FAB & $11.2 \pm 3.0$ & $17.6 \pm 0.6$ & $<0.001$ \\
\hline Verbal fluency & & & \\
\hline 1. Animal naming test & $9.8 \pm 3.7$ & $14.4 \pm 1.8$ & $<0.001$ \\
\hline 2. FAS battery & $8.8 \pm 3.1$ & $26.0 \pm 3.3$ & $<0.001$ \\
\hline Digit span forward & $5.1 \pm 0.9$ & $6.7 \pm 0.8$ & $<0.001$ \\
\hline Digit span backward & $3.4 \pm 0.7$ & $4.6 \pm 0.7$ & $<0.001$ \\
\hline Corsi span forward & $4.7 \pm 1.0$ & $6.0 \pm 0.5$ & $<0.001$ \\
\hline Story recall (immediate) & $9.6 \pm 3.2$ & $13.3 \pm 1.3$ & $<0.001$ \\
\hline Story recall (delayed) & $7.9 \pm 3.0$ & $11.9 \pm 1.1$ & $<0.001$ \\
\hline Stroop effect (seconds) & $161.8 \pm 78.6$ & $95 \pm 12.8$ & 0.002 \\
\hline RAVLT & & & \\
\hline A1 & $5.1 \pm 1.5$ & $5.2 \pm 0.7$ & 0.75 \\
\hline A2 & $6.3 \pm 1.9$ & $8.2 \pm 0.7$ & $<0.001$ \\
\hline A3 & $7.0 \pm 2.2$ & $9.2 \pm 0.8$ & $<0.001$ \\
\hline A4 & $7.1 \pm 2.1$ & $10.8 \pm 1.1$ & $<0.001$ \\
\hline A5 & $7.9 \pm 2.3$ & $11.4 \pm 1.4$ & $<0.001$ \\
\hline IR-A & $6.3 \pm 2.6$ & $10.8 \pm 2.0$ & $<0.001$ \\
\hline DR-A & $5.9 \pm 2.3$ & $10.6 \pm 1.4$ & $<0.001$ \\
\hline Recognition & $9.4 \pm 2.6$ & $12.2 \pm 1.4$ & $<0.001$ \\
\hline DR-A & & & \\
\hline
\end{tabular}

$\mathrm{DR}-\mathrm{A}=$ delayed recall list $\mathrm{A} ; \mathrm{FAB}=$-frontal assessment battery; IR-A immediate recall list A; MMSE = Mini-Mental Status Examination; MoCA = Montreal Cognitive Assessment; RAVLT = Rey's Auditory Verbal and learning test. 


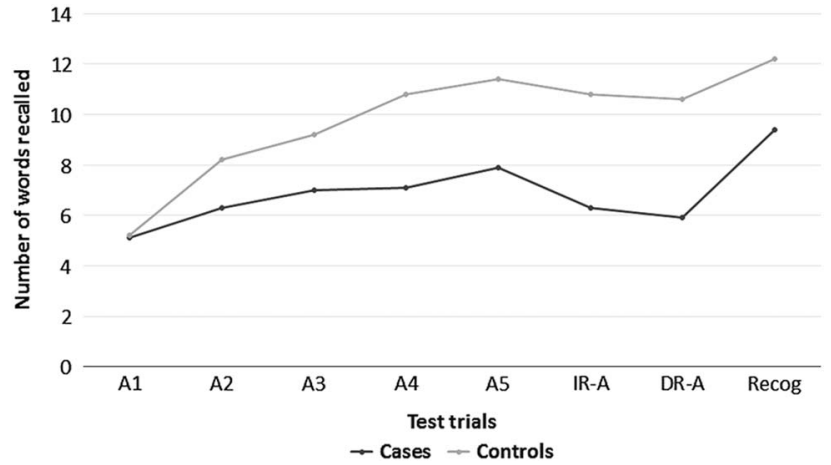

Figure 1: Results of Rey's Auditory Verbal Learning Test in cases and controls.

\section{Correlation of CAG Repeats and Clinical Variables with Neuropsychological Scores}

A significant negative correlation was observed between UHDRS motor scores and neuropsychological tests that included the MMSE, MoCA, FAB, FAS, digit span forward-backward, and story recall. However, there was no correlation with CAG trinucleotide repeat length.

\section{Correlation of TMS Parameters with Neuropsychological Tests}

cSP was found to correlate with cognitive impairment. Prolonged cSP was associated with poor performance on the FAB, story recall, and the AVLT. There was no correlation with SICI.

\section{DisCUSSION}

In our study, we have investigated cortical excitability changes, central motor pathways, cortical inhibitory circuits, and cognition in 32 patients with $\mathrm{HD}$, which is the largest sample to date for such research. We also attempted to correlate the cortical excitability changes with cognitive impairment with the intention to identify the neurotransmitter and neural circuitry abnormality underlying the cognitive impairment. Our study contributes to the literature by providing information about the pathophysiological processes involved in the disease.

\section{Transcranial Magnetic Stimulation}

Previous studies have addressed motor cortical excitability with assessment of MT, CMCT, and SP, and with conflicting results. The reasons for this could be differences in the stage of the disease during the study, the TMS protocols, patient characteristics, and the possibility of chorea interfering with muscle contraction. The present study did not show any difference in RMT, CMCT, and SP between patients and controls. This is in agreement with the work of several other researchers who did not find any difference in RMT or MEP amplitude between HD patients and controls. ${ }^{19-22}$ There are studies that have shown increased motor cortical excitability. ${ }^{23,24}$ The altered excitability of the corticospinal system has been attributed to a mutated protein in the brain ${ }^{23,25,26}$ or to basal ganglia dysfunction. ${ }^{26}$

We have found slight prolongation of the SP, which was not statistically significant. Prolonged SP has been described in other studies. ${ }^{27,28}$ The duration of the SP has also been shown to correlate significantly with the severity of chorea. ${ }^{19}$ The mechanisms underlying the prolonged cortical SP in HD remain unclear. One explanation could be differences in the prestimulus electromyographic (EMG) activity level. ${ }^{29}$ It appears that loss of striatal neurons leads to increased thalamocortical facilitation and increased activity of the cortical inhibitory interneurons, thereby impairing resumption (restart) of voluntary EMG activity. ${ }^{27} \mathrm{SP}$ is $\mathrm{GABA}_{\mathrm{B}}$-mediated, and increased levels of GABA in the corticostriatal pathway has been demonstrated in HD. ${ }^{30}$

SICI was first described by Kujirai et al. ${ }^{15}$ when a subthreshold CS was followed by a suprathreshold TS at an ISI of 1-6 ms, and the CS inhibited the TS. SICI likely has an intracortical origin and is a measure for evaluating changes in cortical excitability. ${ }^{15,31}$ SICI is being mediated by $\mathrm{GABA}_{\mathrm{A}}$ receptors. ${ }^{32}$ It involves two phases, the first of which reflects refractoriness or excitability changes in axons, and the second phase is due to synaptic inhibition. ${ }^{33}$ Paired TMS with the subthreshold CS below and suprathreshold TS at ISIs of 8-30 ms induce an increase in the test MEP amplitude that is known as ICF. ICF originates in the cortex and is mediated by glutaminergic neurons. ${ }^{34}$

In the paired-pulse stimulation study, we found a reduction in SICI. Other researchers have obtained a similar result. Abbruzzese et al. ${ }^{26}$ reported significant reduction in SICI and enhancement of ICF. Changes in intracortical inhibition and facilitation correlated with the clinical rating of chorea. Subsequent studies did not show such findings. ${ }^{21,35}$ However, the sample size was smaller in these studies. A recently published study that included 16 premanifest HD and 12 early symptomatic HD patients found reduced SICI, similar to our study, which is the largest sample size published to date. ${ }^{36}$ In another study, SICI was found to have a higher threshold in all patients. ${ }^{23}$

Studies have shown that SICI is $\mathrm{GABA}_{\mathrm{A}}$-mediated. ${ }^{37} \mathrm{~A}$ reduction in the $\mathrm{GABA}_{\mathrm{A}}$ system causes reduced SICI, and overexpression of the glutaminergic system enhances ICF. This alteration in monoamine concentrations results in a change in the pattern of the excitability of neurons. The facilitatory neurons become more susceptible to stimulation as compared to inhibitory neurons. ${ }^{23} \mathrm{How}$ ever, this was not observed in some recent studies. ${ }^{36}$ Paired transcranial stimulation is a more sensitive measure in detecting changes of cortical excitation levels than single stimulation.

A comparison of our present study with previous studies is provided in Table 4.

\section{Cognition in HD}

The HD patients in our study had significant impairment on the neuropsychological tests, suggesting involvement of attention, memory, learning, visuospatial abilities, and executive functions. As with other neuropsychiatric disorders, the presentation of HD varies considerably between individuals. ${ }^{38}$ Some individuals present with more noticeable motor dysfunction, whereas others present primarily with cognitive or psychiatric disturbances. The FAB has been used to evaluate executive function in HD. In a study of $41 \mathrm{HD}$ patients and 53 controls, FAB scores were lower in patients than in the controls $(p<0.001)$. It also helped in differentiating between HD patients in the initial and later stages of the disease. This one-year longitudinal evaluation revealed a global trend toward a worsening in the second score on the FAB. ${ }^{39}$ In the PREDICT-HD study, out of the 18 tests applied, 6 were identified that predict the time to diagnosis, suggesting that these are important markers of prognosis. ${ }^{40}$

In a study of 54 at-risk HD patients, abnormal semantic fluency and visual discrimination learning was noted. ${ }^{41}$ Abnormality was 
Table 4: Comparison of various studies with the present study

\begin{tabular}{|c|c|c|}
\hline Author & Study population & Results \\
\hline Priori et al. ${ }^{19}$ & $16 \mathrm{HD}$ and 28 controls & No difference in MT between patients and controls; MEPs were smaller in patients \\
\hline Nardone et al. ${ }^{21}$ & $12 \mathrm{HD}$ and 15 controls & Reduced ICF \\
\hline Lorenzano et al. ${ }^{22}$ & $11 \mathrm{HD}$ and 11 controls & No change in MEP size; during voluntary contraction, rTMS increased SP duration \\
\hline Schippling et al. ${ }^{23}$ & $\begin{array}{l}8 \text { premanifest HD, } 8 \text { very early symptomatic } \\
\text { HD patients, and } 22 \text { controls }\end{array}$ & $\begin{array}{l}\text { Premanifest and early manifest HD patients had higher RMT and AMT; higher threshold for SICI; } \\
\text { SAI was reduced in early manifest patients and was inversely associated with predicted years to onset } \\
\text { of HD signs }\end{array}$ \\
\hline Meyer et al. ${ }^{24}$ & $\begin{array}{l}34 \mathrm{HD} \text { and } 21 \text { first-degree offspring of } \mathrm{HD} \\
\text { patients }\end{array}$ & $\begin{array}{l}\text { Increased MT in } 10 \% \text { of HD offspring; abnormal MEPs in } 72 \% \text { of patients; MEP abnormalities } \\
\text { correlated with severity of chorea and duration of symptoms }\end{array}$ \\
\hline Hömberg et al. ${ }^{25}$ & $32 \mathrm{HD}$ and 14 at risk & Normal MT, CMCT, MEP latency, and amplitude \\
\hline Abbruzzese et al. ${ }^{26}$ & $11 \mathrm{HD}$ and 12 controls & $\begin{array}{l}\text { No difference in MT in HD and controls; reduced intracortical inhibition; at longer ISIs (10-25 ms). } \\
\text { there was a significantly greater facilitation in the HD group }\end{array}$ \\
\hline Modugno et al. ${ }^{27}$ & $17 \mathrm{HD}$ and 15 controls & Significant prolongation of SP \\
\hline Philpott et al. $2016^{36}$ & $\begin{array}{l}16 \text { Pre-HD, } 12 \text { symptomatic } \mathrm{HD} \text {, and } \\
17 \text { controls }\end{array}$ & Reduced SICI \\
\hline Present study & $32 \mathrm{HD}$ and 30 controls & Reduced SICI \\
\hline
\end{tabular}

$\mathrm{AMT}=$ active motor threshold $\mathrm{CMCT}=$ central motor conduction time; $\mathrm{ICF}=$ intracortical facilitation $; \mathrm{ISI}=$ interstimulus interval; $\mathrm{MEP}=$ motor-evoked potential; RMT = resting motor threshold; $\mathrm{rTMS}=$ repetitive transcranial magnetic stimulation; $\mathrm{SAI}=$ short afferent inhibition; SICI $=$ short-interval intracortical inhibition; $\mathrm{SP}=$ silent period.

also observed for the symbol digit modalities test, the Stroop test, and the direct and indirect circle tracing tests. ${ }^{18}$ Paulsen et al. ${ }^{11}$ analyzed data from the 36-center Huntington's Study Group and reported poor performance on the symbol digit modalities test and all three trials of the Stroop color-word test. The Stroop test and symbol digit substitution tasks are all described as psychomotor performance tasks that make minimal demands on higherlevel cognition, thereby making them particularly sensitive to striatal dysfunction. ${ }^{42}$ Patients with an illness with a duration greater than 8.62 years also show significant differences on the Wisconsin Card Sorting Test. ${ }^{42}$

In another study, mutation carriers who were predicted to convert early $($ mean $=4.0$ years) performed significantly worse than those further from onset (mean $=13.1$ years) on the symbol digit modalities test, the Weschler Adult Intelligence Scale block design subtest, the Stroop test, and the standardized road-map test of directional sense and nondominant hand performance on the Grooved Pegboard Test. ${ }^{43}$

The neural basis for the neuropsychological abnormality is still unknown; however, it has been proposed that the motor circuit (putamen, thalamus, supplementary motor area, and sensorimotor cortices), the parietal cortex, the ventral striatum, and the limbic system (orbitofrontal, cingulate and anterior insular cortices) are disrupted in HD. The insular cortex may be especially important, as it integrates physiological states, and anterior insula activity is abnormal in HD patients. ${ }^{8}$ In HD, the primary site of pathology is thought to be the striatum (dorsal caudate), which is richly connected to the lateral prefrontal cortex via a series of parallel corticostriatal circuits, and so these patients have impaired frontal executive functioning. ${ }^{41}$ This gives rise to poor planning, organization, and set shifting.

\section{Relationship between Cortical Excitability Changes and Cognitive Impairment}

Though we did not find any correlation between the two, it appears that these changes occur in parallel, as evidenced by the significant difference between HD patients and controls in cognitive testing and SICI. Further studies are required to address this issue.

\section{Limitations OF THE STUdy}

Ipsilateral SP was not tested in our patients, as most had difficulty in fully contracting the FDI muscle, and they could also not tolerate the stimulus intensity, which is $100 \%$ of stimulator output. Recording of ipsilateral SP could have contributed to the callosal function in HD patients.

\section{Conclusions}

TMS is a valuable method of evaluating the cortical excitability and central motor pathways in patients with HD. There is reduced SICI, as evidenced by paired stimulation research. Our study has tried to look into the cognitive impairment in HD patients using a battery of nine neuropsychological tests and has found profound impairment in attention, memory, and visuospatial and executive functioning. A comprehensive and sensitive neuropsychological battery to assess cognition in HD is still lacking. Such a battery is required to evaluate outcome, and to predict and track disease progression. It would also be useful in formulating appropriate therapeutic strategies and guidelines for management of the disease. There is also a need for further studies to understand cortical excitability changes and intracortical inhibition, as previous studies have yielded variable results.

\section{Disclosures}

Nitish Kamble, M. Netravathi, B.C. Nagaraju, Abhishek Lenka, Keshav Kumar, V. Sowmya, Sanjeev Jain, and Pramod Kumar Pal received partial financial support (grant recipient) from the Indian Council of Medical Research (no. ICMR/002/208/ 2012/00126). 


\section{REFERENCES}

1. Ross CA, Tabrizi SJ. Huntington's disease: from molecular pathogenesis to clinical treatment. Lancet Neurol. 2011;10:83-98.

2. Atwal RS, Xia J, Pinchev D, Taylor J, Epand RM, Truant R. Huntingtin has a membrane association signal that can modulate huntingtin aggregation, nuclear entry and toxicity. Hum Mol Genet. 2007;16:2600-15.

3. Novak MJU, Tabrizi SJ. Huntington's disease: clinical presentation and treatment. Int Rev Neurobiol. 2011;98:297-323.

4. Lenka A, Kamble NL, Sowmya V, et al. Determinants of onset of Huntington's disease with behavioral symptoms: insight from 92 patients. J Huntingtons Dis. 2015;4:319-24.

5. Albin R, Reiner A, Anderson KD, et al. Preferential loss of striato-external pallidal projection neurons in presymptomatic Huntington's disease. Ann Neurol. 1992;31:425-30.

6. Paulsen JS, Zhao H, Stout JC, et al. Clinical markers of early disease in persons near onset of Huntington's disease. Neurology. 2001;57(4):658-62.

7. Beglinger LJ, Nopoulos PC, Jorge RE. White matter volume and cognitive dysfunction in early Huntington's disease. Cogn Behav Neurol. 2005;18(2):102-7.

8. Montoya A, Pelletier M, Menear M, Duplessis E, Richer F, Lepage M. Episodic memory impairment in Huntington's disease: a meta-analysis. Neuropsychologia. 2006;44(10):1984-94.

9. Craufurd D, Snowden J. Neuropsychological and neuropsychiatric aspects of Huntington's disease. In: Bates G, Harper P, Jones L, eds Huntington's Disease. New York: Oxford University Press; 2002:62-94.

10. Paulsen JS, Hayden M, Stout JC, et al. Preparing for preventive clinical trials: the PREDICT-HD study. Arch Neurol. 2006; 63(6):883-90

11. Paulsen JS, Langbehn DR, Stout JC, et al. Detection of Huntington's disease decades before diagnosis: the PREDICT-HD study. J Neurol Neurosurg Psychiatry. 2008;79(8):874-80.

12. Nopoulos PC, Aylward EH, Ross CA. Smaller intracranial volume in prodromal Huntington's disease: evidence for abnormal neurodevelopment. Brain. 2011;134(1):137-42.

13. Huntington Study Group. Unified Huntington's Disease Rating Scale: reliability and consistency. Mov Disord. 1996;11:136-42.

14. Rossini PM, Caramia MD, Zarola F. Mechanisms of nervous propagation along central motor pathways: noninvasive evaluation in healthy subjects and in patients with neurological diseases. Neurosurgery. 1987;20:183-91.

15. Kujirai T, Caramia MD, Rothwell JC, et al. Corticocortical inhibition in human motor cortex. J Physiol. 1993;471:501-19.

16. Dubois B, Litvan I. The FAB: a frontal assessment battery at bedside. Neurology. 2000;55(11):1621-6.

17. Corsi PM. Human memory and the medial temporal region of the brain. Diss Abstr Intl. 1972;34:891B.

18. Stout JC, Jones R, Labuschagne I, et al. Evaluation of longitudinal 12- and 24-month cognitive outcomes in premanifest and early Huntington's disease. J Neurol Neurosurg Psychiatry. 2012;83:687-94.

19. Priori A, Berardelli A, Inghilleri M, Polidori L, Manfredi M. Electromyographic silent period after transcranial brain stimulation in Huntington's disease. Mov Disord. 1994;9:178-82.

20. Eisen A, Bohlega S, Bloch M, Hayden M. Silent periods, longlatency reflexes and cortical MEPs in Huntington's desease and at-risk relatives. Electroencephalogr Clin Neurophysiol. 1989;74:444-9.

21. Nardone R, Lochner P, Marth R, Ausserer H, Bratti A, Tezzon F. Abnormal intracortical facilitation in early-stage Huntington's disease. Clin Neurophysiol. 2007;118:1149-54.

22. Lorenzano C, Dinapoli L, Gilio F, et al. Motor cortical excitability studied with repetitive transcranial magnetic stimulation in patients with Huntington's disease. Clin Neurophysiol. 2006; 117:1677-81.
23. Schippling S, Schneider SA, Bhatia KP, et al. Abnormal motor cortex excitability in preclinical and very early Huntington's disease. Biol Psychiatry. 2009;65:959-65.

24. Meyer BU, Noth J, Lange HW, et al. Motor responses evoked by magnetic brain stimulation in Huntington's disease. Electroencephalogr Clin Neurophysiol. 1992;85:197-208.

25. Hömberg V, Lange HW. Central motor conduction to hand and leg muscles in Huntington's disease. Mov Disord. 1990;5:214-8.

26. Abbruzzese G, Buccolieri A, Marchese R, Trompetto C, Mandich P, Schieppati M. Intracortical inhibition and facilitation are abnormal in Huntington's disease: a paired magnetic stimulation study. Neurosci Lett. 1997;228:87-90.

27. Modugno N, Currà A, Giovannelli $\mathrm{M}$, et al. The prolonged cortical silent period in patients with Huntington's disease. Clin Neurophysiol. 2001;112:1470-4.

28. Roick A, von Giesen HJ, Lange HW, Benecke R. Postexcitatory inhibition in Huntington's disease. Mov Disord. 1992;7:27.

29. Cantello R, Gianelli M, Civardi C, Mutani R. Magnetic brain stimulation: the silent period after the motor evoked potential. Neurology. 1992;42:1951-9.

30. Werhahn KJ, Kunesch E, Noachtar S, Benecke R, Classen J. Differential effects on motorcortical inhibition induced by blockade of GABA uptake in humans. J Physiol. 1999;517:591-7.

31. Modugno N, Currà A, Conte $\mathrm{A}$, et al. Depressed intracortical inhibition after long trains of subthreshold repetitive magnetic stimuli at low frequency. Clin Neurophysiol. 2003;114:2416-22.

32. Ziemann U, Lönnecker S, Steinhoff BJ, Paulus W. Effects of antiepileptic drugs on motor cortex excitability in humans: a transcranial magnetic stimulation study. Ann Neurol. 1996; 40:367-78.

33. Fisher RJ, Nakamura Y, Bestmann S, Rothwell JC, Bostock H. Two phases of intracortical inhibition revealed by transcranial magnetic threshold tracking. Exp Brain Res. 2002;143:240-8.

34. Ziemann U, Chen R, Cohen LG, Hallett M. Dextromethorphan decreases the excitability of the human motor cortex. Neurology. 1998;51:1320-4.

35. Hanajima R, Ugawa Y, Terao Y, et al. Intracortical inhibition of the motor cortex is normal in chorea. J Neurol Neurosurg Psychiatry. 1999;66:783-6.

36. Philpott AL, Cummins TD, Bailey NW, Churchyard A, Fitzgerald PB, Georgiou-Karistianis N. Cortical inhibitory deficits in premanifest and early Huntington's disease. Behav Brain Res. 2016;296:311-7.

37. Hanajima R, Ugawa Y, Terao Y, et al. Paired-pulse magnetic stimulation of the human motor cortex: differences among I waves. J Physiol. 1998;509:607-18.

38. Rosas HD, Salat DH, Lee SY, et al. Cerebral cortex and the clinical expression of Huntington's disease: complexity and heterogeneity. Brain. 2008;131(4):1057-68.

39. Rodrigues GR, Souza CP, Cetlin RS, et al. Use of the frontal assessment battery in evaluating executive dysfunction in patients with Huntington's disease. J Neurol. 2009;256(11):1809-15.

40. Harrington DL, Smith MM, Zhang Y, et al. Cognitive domains that predict time to diagnosis in prodromal Huntington disease. J Neurol Neurosurg Psychiatry. 2012;83(6):612-9.

41. Lawrence AD, Hodges JR, Rosser AE, et al. Evidence for specific cognitive deficits in preclinical Huntington's disease. Brain. 1998;121(7):1329-41.

42. Brandt J, Inscore AB, Ward J, et al. Neuropsychological deficits in Huntington's disease gene carriers and correlates of early "conversion. J Neuropsychiatry Clin Neurosci. 2008;20(4):466-72.

43. Brandt J, Shpritz B, Codori AM, Margolis R, Rosenblatt A. Neuropsychological manifestations of the genetic mutation for Huntington's disease in presymptomatic individuals. J Int Neuropsychol Soc. 2002;8:918-24. 